Supplementary information

\title{
The impact of periodic polarization on groundwater denitrification in
} bioelectrochemical systems

\author{
Xiaofei Wang ${ }^{\text {ab }}$, Antonin Prévoteau ${ }^{\text {ab }}$ and Korneel Rabaey ${ }^{a b^{*}}$ \\ a Center for Microbial Ecology and Technology \\ (CMET), Ghent University, Coupure Links 653, 9000, Ghent, Belgium \\ b Centre for Advanced Process Technology for Urban Resource Recovery (CAPTURE), Frieda Saeysstraat 1, 9000 Ghent, \\ Belgium \\ * Corresponding author. E-mail address: korneel.rabaey@ugent.be. URL: http://www.capture-resources.be
}

16 pages of supplementary information are provided for a completed manuscript: SI1 - SI5 for material and method, SI6-SI9 for results and discussion, including 8 figures (Figure S1-S8). 


\section{SI1. MEC construction}

Each MEC consisted of two compartments $\left(5 \times 20 \times 2 \mathrm{~cm}^{3}\right)$ constructed by identical Perspex frames and plates. A cation exchange membrane (CEM) (Nafion 117, Dupont, USA) was used to separate the catholyte and anolyte. The CEM was soaked in $5 \mathrm{wt} \% \mathrm{NaCl}$ for at least $24 \mathrm{~h}$ prior to operation. The anode material was an iridium mixed metal oxide (Ir MMO) coated titanium-electrode mesh $\left(\mathrm{TiO}_{2} / \mathrm{IrO}_{2}, 0.35 / 0.65\right.$, Magneto Special Anodes, The Netherlands) and the cathode was densely packed granular graphite (size 3.35-8 mm, DESOTEC, Belgium) with a 304 stainless steel wire mesh (surface area $5 \mathrm{~cm} \times 20 \mathrm{~cm}$, Mesh size $495 \mu \mathrm{m}$, open surface $49.8 \%$, wire diameter $200 \mu \mathrm{m}$, Solana, Belgium) as the current collector. A spacer (turbulence promoter mesh, $1 \mathrm{~mm}$ thick, ElectroCell, Denmark) was used in each chamber to prevent the contact between the electrodes and the membrane. The membrane, the anode and the current collector in the cathode compartment had the same projected surface area of $100 \mathrm{~cm}^{2}$. 


\section{SI2. Analytical methods for liquid samples}

Ionic conductivity and pH were measured with a Consort C6010 meter (Consort, Belgium) and a 744 $\mathrm{pH}$ meter (Metrohm, Switzerland) respectively. Ion concentrations were measured by a 930 compact ion chromatography (Metrohm, Switzerland) with a conductivity detector. A Metrosep A Supp 5$150 / 4.0$ column, with the eluent of $1.0 \mathrm{mM} \mathrm{NaHCO}_{3}$ and $3.2 \mathrm{mM} \mathrm{Na}_{2} \mathrm{CO}_{3}$, was applied to inorganic anions $\left(\mathrm{NO}_{2}{ }^{-}, \mathrm{NO}_{3}{ }^{-}\right.$, etc.) measurements, and a Metrosep $\mathrm{C} 6-150 / 4$ column, with the eluent of $1.7 \mathrm{mM} \mathrm{HNO} 3,1.7 \mathrm{mM}$ dipicolinic acid, was used to determine inorganic cations $\left(\mathrm{Ca}^{2+}, \mathrm{Mg}^{2+}, \mathrm{NH}^{+}\right.$ etc.). Prior to analysis, the samples were filtered through $0.20 \mu \mathrm{m}$ ChromafilXtra filter (MacheryNagel, USA). 


\section{SI3. $\mathrm{N}_{2} \mathrm{O}$ measurement by gas chromatography}

$\mathrm{N}_{2} \mathrm{O}$ produced in the cathode compartment consisted of two part: the assumed to be saturated $\mathrm{N}_{2} \mathrm{O}$ in the liquid phase and the $\mathrm{N}_{2} \mathrm{O}$ emitted to the gas phase.

- Gas phase $\mathrm{N}_{2} \mathrm{O}$ :

$2 \mathrm{~mL}$ gas was sampled directly from the headspace with a needle penetrating the rubber cap of the cathodic recirculation bottle. the gas-proof valve placed between the needle and the syringe was immediately closed to isolate the gas sample and the air. The percentage of $\mathrm{N}_{2} \mathrm{O}$ in the gas phase was measured directly by injecting this sample to compact gas chromatography (CGC) 4.0 (Global Analyser Solutions, Breda, The Netherlands), equipped with a Molsieve 5A pre-column and Porabond $\mathrm{Q}$ column for $\mathrm{N}_{2}$ and a Rt-Q-bond pre-column and column for $\mathrm{N}_{2} \mathrm{O}$. Concentrations of gases were determined by means of a thermal conductivity detector.

The total amount of $\mathrm{N}_{2} \mathrm{O}$ in the headspace gas is calculated as Eq.1: ${ }^{1}$

$$
n_{-}{ }_{S S}=V_{-H S} \cdot x P / R T
$$

$\mathrm{n}_{-} \mathrm{Hs}$ : amount of $\mathrm{N}_{2} \mathrm{O}$ in headspace (mol)

$V_{-}$Hs: volume of the headspace $(L)$

$\mathrm{x}$ : the percent of $\mathrm{N}_{2} \mathrm{O}$ in the headspace (\%) -given by CGC

P: pressure of the headspace (atm)

R: the ideal gas constant $(0.0821 \mathrm{~L} \mathrm{~atm} / \mathrm{mol} / \mathrm{K})$

T: temperature (room temperature $22^{\circ} \mathrm{C}=295.15 \mathrm{~K}$ )

- Liquid phase $\mathrm{N}_{2} \mathrm{O}$ :

As the cathodic recirculation bottle is an isolated environment from the air, the dissolved $\mathrm{N}_{2} \mathrm{O}$ can be calculated by the gas-liquid equilibrium (Eq. 2). ${ }^{2}$

$n_{-l i q}=k R T \cdot \frac{n_{-H S}}{V_{-H S}}=k x P \cdot V_{-l i q}$

$\mathrm{N}_{-}$liq: amount of $\mathrm{N}_{2} \mathrm{O}$ in the liquid phase (mol)

$V_{\text {liq }}$ : the volume of the liquid phase (L)

k: solubility coefficient $\mathrm{N}_{2} \mathrm{O}$ in water at $22^{\circ} \mathrm{C}\left(0.027 \mathrm{~mol} / \mathrm{L} / \mathrm{atm}^{3}\right)$

Thus the $\mathrm{N}_{2} \mathrm{O}$ concentration is calculated as Eq.3:

$C_{N 2 O}=\frac{n_{\_} H S+n_{\_l i q}}{V_{\_l i q}}$ 


\section{SI4. Energy calculation}

The energy consumption is calculated 1 ) by the energy cost treating per unit volume of groundwater (eq.4); 2) by the energy cost for the removal of per unit mass of $\mathrm{NO}_{3}{ }^{-}-\mathrm{N}$ (eq.5), where $\mathrm{E}$ is the wholecell voltage, $\mathrm{I}$ is the current, $\mathrm{t}$ is the time and $\mathrm{V}$ is the treated volume of the $\mathrm{SGW}$, and $\mathrm{m}_{\mathrm{N}}$ is the mass of $\mathrm{NO}_{3}{ }^{-} \mathrm{N}$ removed.

Volume based energy calculation $\left(\mathrm{kWh} \cdot \mathrm{m}^{-3}\right)=\frac{E \int_{0}^{t} I(t) d t}{V}$

Mass based energy calculation $\left(\mathrm{kWh} \cdot \mathrm{kg}^{-1} \mathrm{NO}_{3}^{-}-\mathrm{N}\right)=\frac{E \int_{0}^{t} I(t) d t}{m_{N}}$ 


\section{SI5. microbial analysis by Illumina 16 S rRNA gene amplicon sequencing}

The graphite granules with EABs in the cathodic compartment were sampled every two months and stored at $-20^{\circ} \mathrm{C}$ until further processing. DNA extraction was performed by means of bead beating with a PowerLyzer (Qiagen, Venlo, the Netherlands) and phenol/chloroform extraction. Genomic DNA extract $(10 \mu \mathrm{L})$ was send out to LGC genomics $\mathrm{GmbH}$ (Berlin, Germany) for library preparation and sequencing on an Illumina Miseq platform with v3 chemistry with the primers 341F (5'-CCT ACG GGN GGC WGC AG -3') and 785Rmod (5'-GAC TAC HVG GGT ATC TAA KCC-3') ${ }^{4}$. Mothur (v.1.42.3) was used to assemble reads into contigs, perform alignment-based quality filtering (alignment to the mothurreconstructed SILVA SEED alignment, v. 138), remove chimeras (vsearch v2.13.0), assign taxonomy using a naïve Bayesian classifier ${ }^{5}$ and SILVA NR v138 and cluster contigs into OTUs at $97 \%$ sequence similarity. All statistical sequence analysis was performed in R (v3.3.2). Detailed information on the DNA extraction methods, gene amplicon sequencing analysis, clone library methods and data processing can be found in previous work ${ }^{6}$. 


\section{SI6. Impact of OCP/polarization intervals on denitrification performance}

$\mathrm{OCP} /$ polarization interval tests were performed on R2 between day 80 and day 109 as described in section 2.2.2. While the current of R1 remained stable under continuous polarization $\left(I_{-} 1=-18.6 \pm 0.3\right.$ $\mathrm{mA}$ ), the electrochemical performance of $\mathrm{R} 2$ varied with the OCP/polarization intervals (Figure S1). The highest (most negative) average faradaic current (I_2 $f$ ) around $-26.5 \mathrm{~mA}$ was observed at $10 \mathrm{~s} / 10 \mathrm{~s}$ and 30s/30s intervals. The absolute value of cathodic peak current (I___max) initially increased with the halfperiod of polarization applied, then stabilized at its maximum $(-42.0 \pm 0.5 \mathrm{~mA})$ from $30 \mathrm{~s} / 30 \mathrm{~s}$. The highest cumulative charge ratio $\left(Q_{-} 2 / Q_{-} 1=78 \%\right)$ and faradaic charge ratio $\left(Q_{-}{ }_{-} f / Q_{-} 1=70 \%\right)$ both appeared at $30 \mathrm{~s} / 30 \mathrm{~s}$ interval, followed by $10 \mathrm{~s} / 10 \mathrm{~s}$ interval, with comparable ratios $\left(Q_{-} 2 / Q_{-} 1=77 \%\right.$ and $Q_{-}{ }_{-} f\left(Q_{-} 1=69 \%\right)$ (Figure S1).

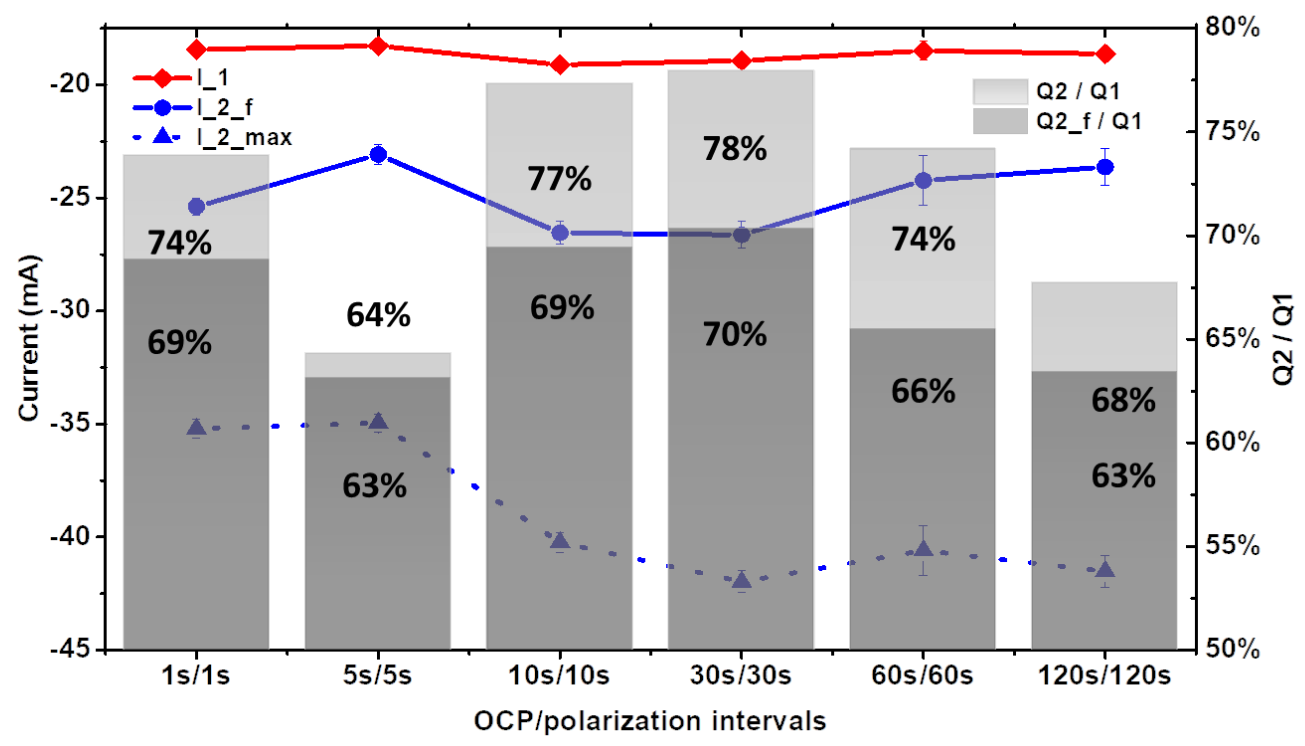

Figure $S 1$ The average current of $R 1$ (I_1) (red diamond) under continuous polarization and $R 2$ (I_2f (blue circles) and I_2_max (blue triangles)) at each $O C P /$ polarization interval, and the cumulative charge ratio $\left(Q_{2} 2 / Q_{-} 1\right)$ (light grey bars) and faradaic charge ratio $\left(Q_{-} 2 f / Q_{-}\right)$(dark grey bars) between $R 2$ and $R 1$

A recent study ${ }^{7}$ compared the performance between acetate-fed microbial anodes with high and low capacitance in serially stacked microbial fuel cells. They found that when a high-capacitance anode was used, the cells were more resilient to electron donor (acetate) limiting conditions, and the performance recovered easier when acetate supply was refreshed. A mechanism is thus proposed by them: the electron generation capacity of the EABs on a high-capacitance bioanode is higher than the 
electron flow when the substrate is not limiting. The surplus electrons would be stored as capacitive charge (or pseudo-capacitive charge as the charge was generated by acetate oxidation) in the bioanode. When the substrate is insufficient, and the stored surplus electrons would be discharged as a compensation to the electron flow. In our study, the electron donor was the power supply to the biocathode, instead of the acetate. Assuming the biocathode was able to store the electrons as well, during the OCP, when external electron supply is stopped, a fraction of the stored electrons (pseudocapacitive charge) would be released for denitrification. A longer OCP period may therefore induced a larger electron deficit for the EAB, thus resulting in a higher current peak once the cathode is repolarized. The total capacitive charge (including pseudo-capacitive charge) of R2 ( $Q_{-}{ }_{-}$c) of a single peak in one polarization cycle increased with the increase of polarization intervals from $5 s / 5 s$ to $60 \mathrm{~s} / 60 \mathrm{~s}$ (Figure S2). However, similar value of $Q_{-} 2$ c were obtained at both $60 \mathrm{~s} / 60 \mathrm{~s}$ and $120 \mathrm{~s} / 120 \mathrm{~s}$. $60 \mathrm{~s}$ OCP might be long enough to consume all the stored electrons, thus longer OCP period would not contribute to more capacitive charge when repolarized. As the EABs were starving during OCP, the cell growth and bioactivity might be impacted over time when applying longer intervals. The cumulative capacitive charge of R2 at the transit from OCP to polarization was calculated for a longer term (eg. $5 \mathrm{~h}$ ) at each polarization interval. The highest values were observed at $10 \mathrm{~s} / 10 \mathrm{~s}, 30 \mathrm{~s} / 30 \mathrm{~s}$ and $60 \mathrm{~s} / 60 \mathrm{~s}$ (Figure S2), around $10 \%$ of the total cumulative (faradaic + capacitive) charge. As the total polarization time in all the intervals are the same $(2.5 \mathrm{~h})$, the higher polarization frequency of the shorter intervals compensated the lower capacitive charge in a single peak, resulting in similar cumulative capacitive charge at the three intervals. 


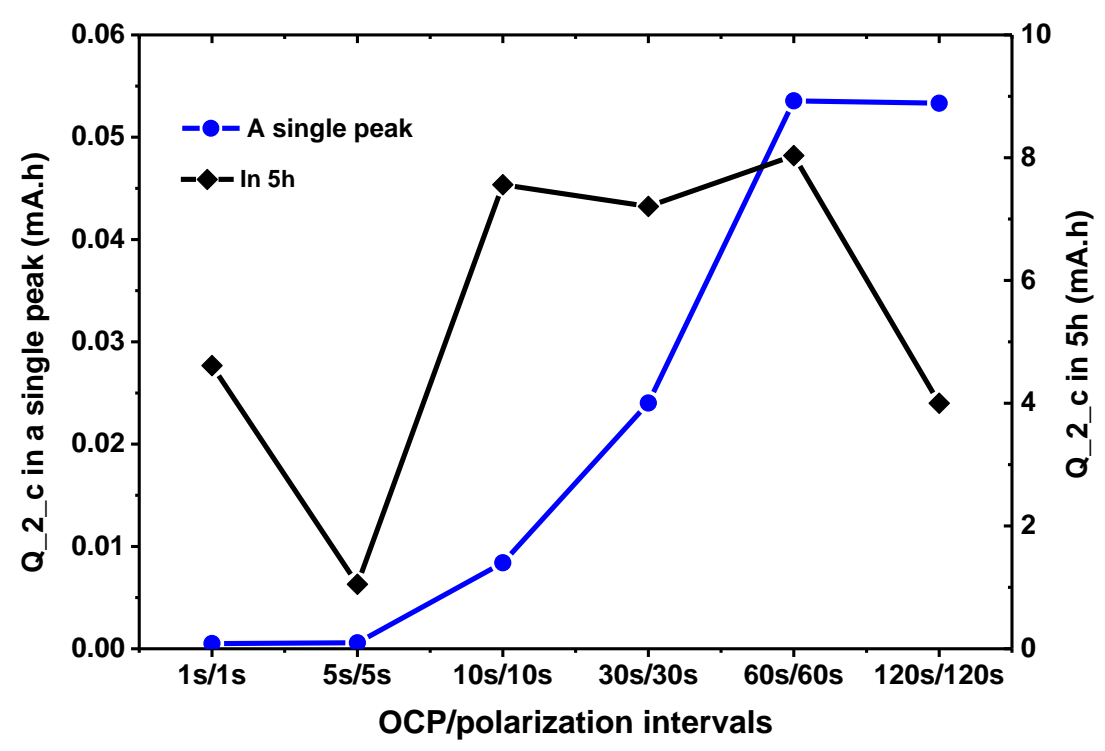

Figure $S 2$ Capacitive charge ( $\left.Q_{-}{ }_{2} c\right)$ of a single peak in one polarization cycle (blue circles) and the cumulative capacitive charge in 5 h (black diamond) at different OCP/polarization intervals in $R 2$.
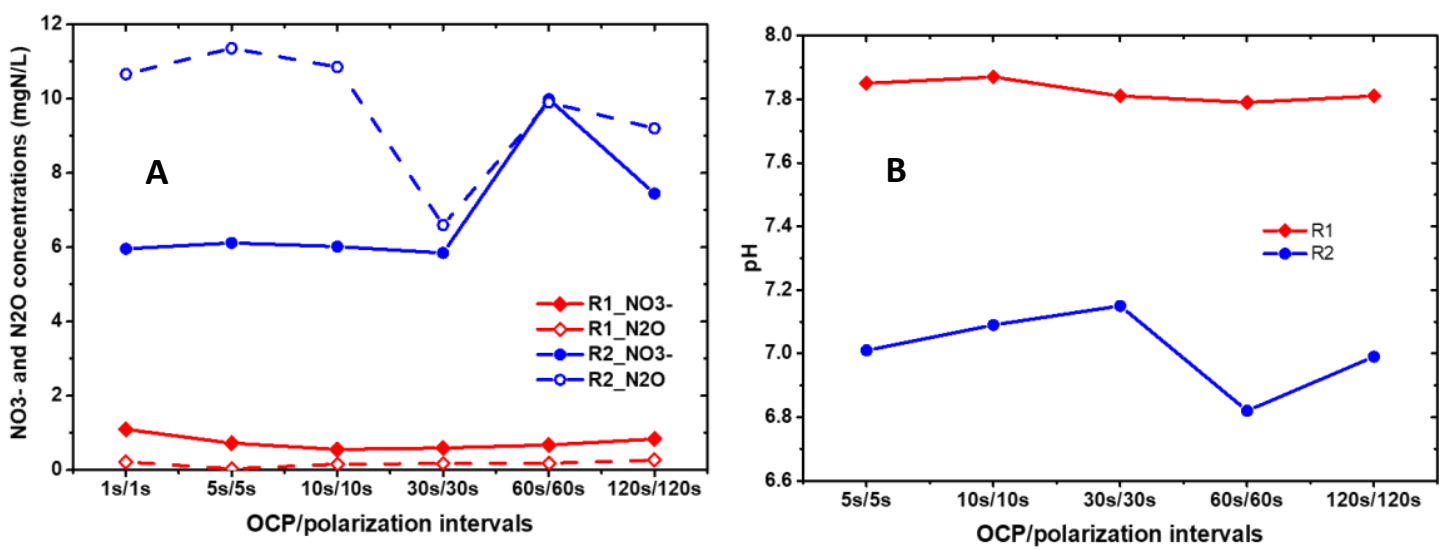

Figure $\mathrm{S} 3$ Nitrate and $\mathrm{N}_{2} \mathrm{O}$ concentration $(A)$ and $p H(B)$ in the effluent of $\mathrm{R} 1$ under continuous polarization and $\mathrm{R} 2$ under periodic polarization at each $\mathrm{OCP} /$ polarization interval.

The best denitrification performance of R2 occurred at 30s/30s interval with $82 \%$ nitrate removal and the lowest $\mathrm{N}_{2} \mathrm{O}$ production $(6.6 \mathrm{mg} / \mathrm{L})$, while nearly full denitrification was still observed in the continuously polarized R1 (Figure S3A). Nitrite was undetectable in both MECs. Higher concentration of $\mathrm{N}_{2} \mathrm{O}$ was produced at shorter intervals (1s/1s to $\left.10 \mathrm{~s} / 10 \mathrm{~s}\right)$ compared to $30 \mathrm{~s} / 30 \mathrm{~s}$, though the same level of nitrate was detected in the effluent $\left(6.0 \pm 0.1 \mathrm{mg} \mathrm{NO}_{3}^{-}-\mathrm{N} / \mathrm{L}\right)$ (Figure S3A). The incompleted denitrification was likely caused by the periodic deficit of electron induced by the OCP periods. When external electron donors were limited, $\mathrm{N}_{2} \mathrm{O}$ tended to accumulate as an intermediate and release to 
the headspace of the cathodic recirculation bottle. When the biocathode was repolarized, nitrate was easier to be taken up by the EABs than $\mathrm{N}_{2} \mathrm{O}$. At long intervals (60s/60s and $120 \mathrm{~s} / 120 \mathrm{~s}$ ), both nitrate and $\mathrm{N}_{2} \mathrm{O}$ concentrations in $\mathrm{R} 2$ were higher than those at 30s/30s interval (Figure S3A). The relatively long OCP period might impact the activity of the denitrifiers. Previous study observed that with longer electron donor starvation, longer time was required by an acetate-fed microbial anode to recover their initial performance after the electron donor was available again ${ }^{7}$. This finding could also explain the loss of denitrification performance in this study with longer OCP period, though the aforementioned study investigated external electron donor limitation in the time range of several days in a MFC. The highest $\mathrm{pH}(7.15)$ in the effluent of $\mathrm{R} 2$ was also observed at 30s/30s interval, while a higher stable $\mathrm{pH}$ $(7.8 \pm 0.03)$ was observed in the effluent of $\mathrm{R} 1$ (Figure S3B). The $\mathrm{pH}$ variation was in accordance with the electron availability and the denitrification performance. When more electrons were available, more faradaic current was generated and more nitrate was removed with less intermediates accumulating. In the meantime, more protons were consumed in the denitrification process, leading to $\mathrm{pH}$ increase.

Based on the highest charge ratio and the best nitrate removal performance amongst the periodic polarizations tested, the interval of 30s/30s was chosen for the long term periodic polarization of R2. 


\section{SI7. Calcium concentration in R1 and R2 when cathodic effluent was directed to the anolyte recirculation.}

The $\mathrm{pH}$ of anolyte was $2.7 \pm 0.1$ with manual refreshment. However, between day 153 and day 189, the anolyte was neutralized to $\mathrm{pH} 7.3 \pm 0.3$ by the cathodic outflows. With less protons available to migrate from the anolyte to the catholyte across the CEM, the $\mathrm{pH}$ of the cathodic effluent of R1 increased from $7.7 \pm 0.2$ to $8.2 \pm 0.2$, and that of $R 2$ increased from $7.1 \pm 0.2$ to $8.0 \pm 0.2$. According to a simulation using Hydra- Medusa software ${ }^{8}$ (Figure $\mathrm{S} 4$ ), at $\mathrm{pH} \geq 8$, a majority of calcium can precipitate as $\mathrm{CaCO}_{3}$ with the bicarbonate in the synthetic groundwater. As such, the dissolved calcium concentration in the catholyte of both reactors decreased by $60 \%$ (Figure S5) and SEM results confirmed the appearance of calcium-containing precipitates on the surface of the biocathodes (Figure S6). The calcium precipitation could lead to less buffering and limit the carbon availability for microbial growth. For a cathode poised at a constant potential, the overpotential available for denitrification decreased with the increase of $\mathrm{pH}$, since the apparent formal potential of nitrate couple decreased with alkalinity according to the Pourbaix diagram of the nitrogen species. This, coupling with the potential fouling of the cathode, induced a less negative cathodic current and a decrease of the associated denitrification rate. An electrochemical softening step could be implemented prior to the denitrification process to prevent the calcium precipitation caused by $\mathrm{pH}$ variation ${ }^{9-11}$ but likely a throttling of inflow towards the anode leading to more proton transfer would enable maintaining the lower $\mathrm{pH}$ level. 


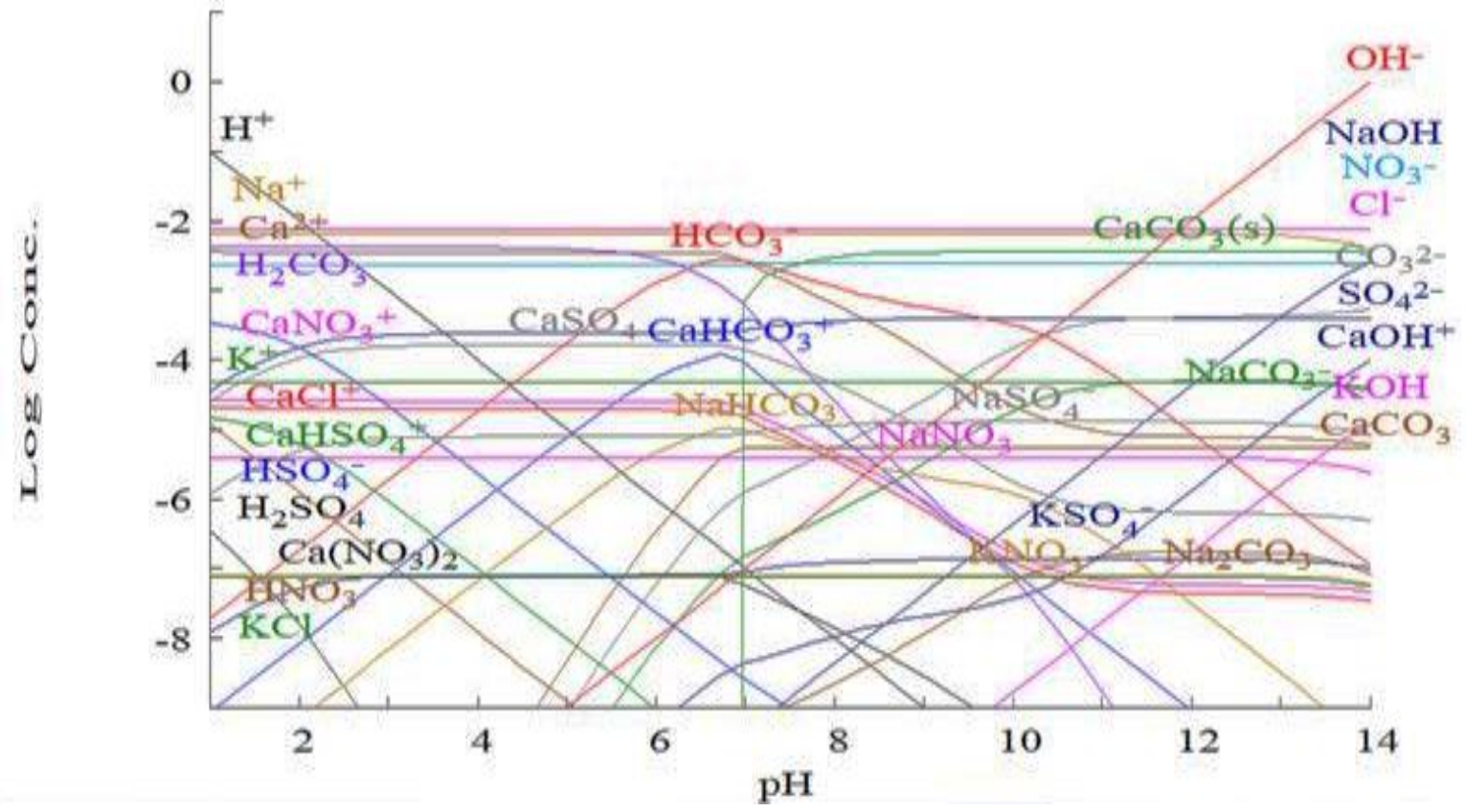

Figure $S 4$ The complexes and solid phases that may occur at different $\mathrm{pH}$ with the composition of the synthetic groundwater based on chemical equilibrium, simulation by Hydra-Medusa software. Concentrations are in mol/L.

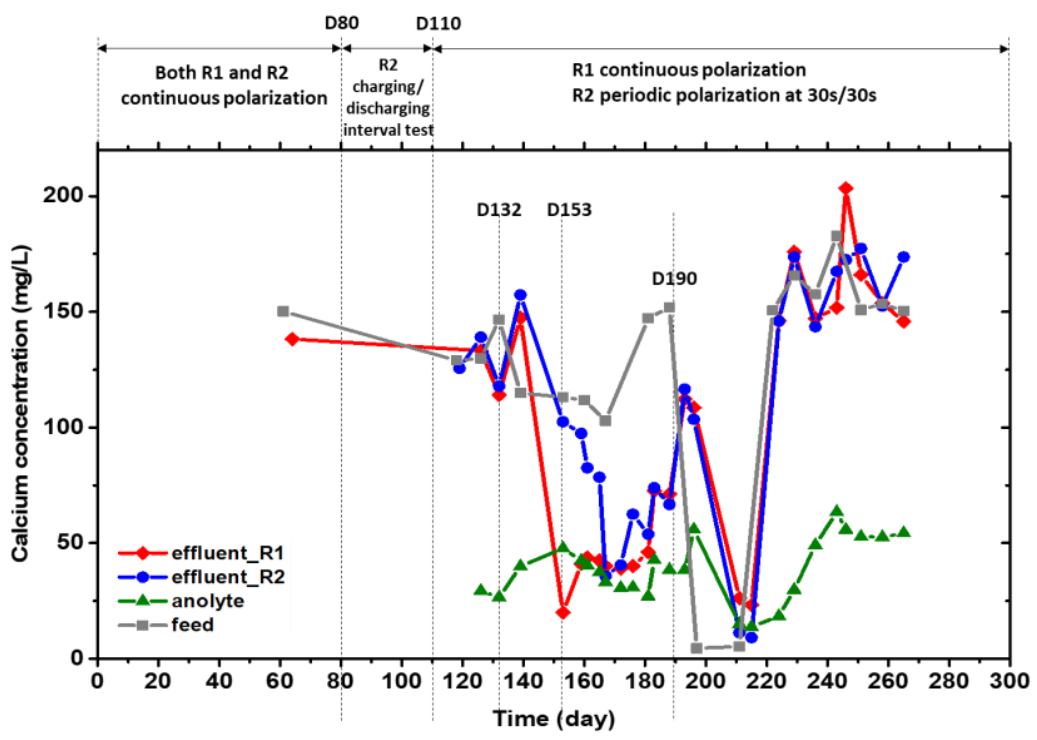

Figure $S 5$ Calcium concentrations in the cathodic effluents from R1 (red diamonds) and R2 (blue circles), and in the anolyte (green triangle) and the SGW feed (gray squares). 

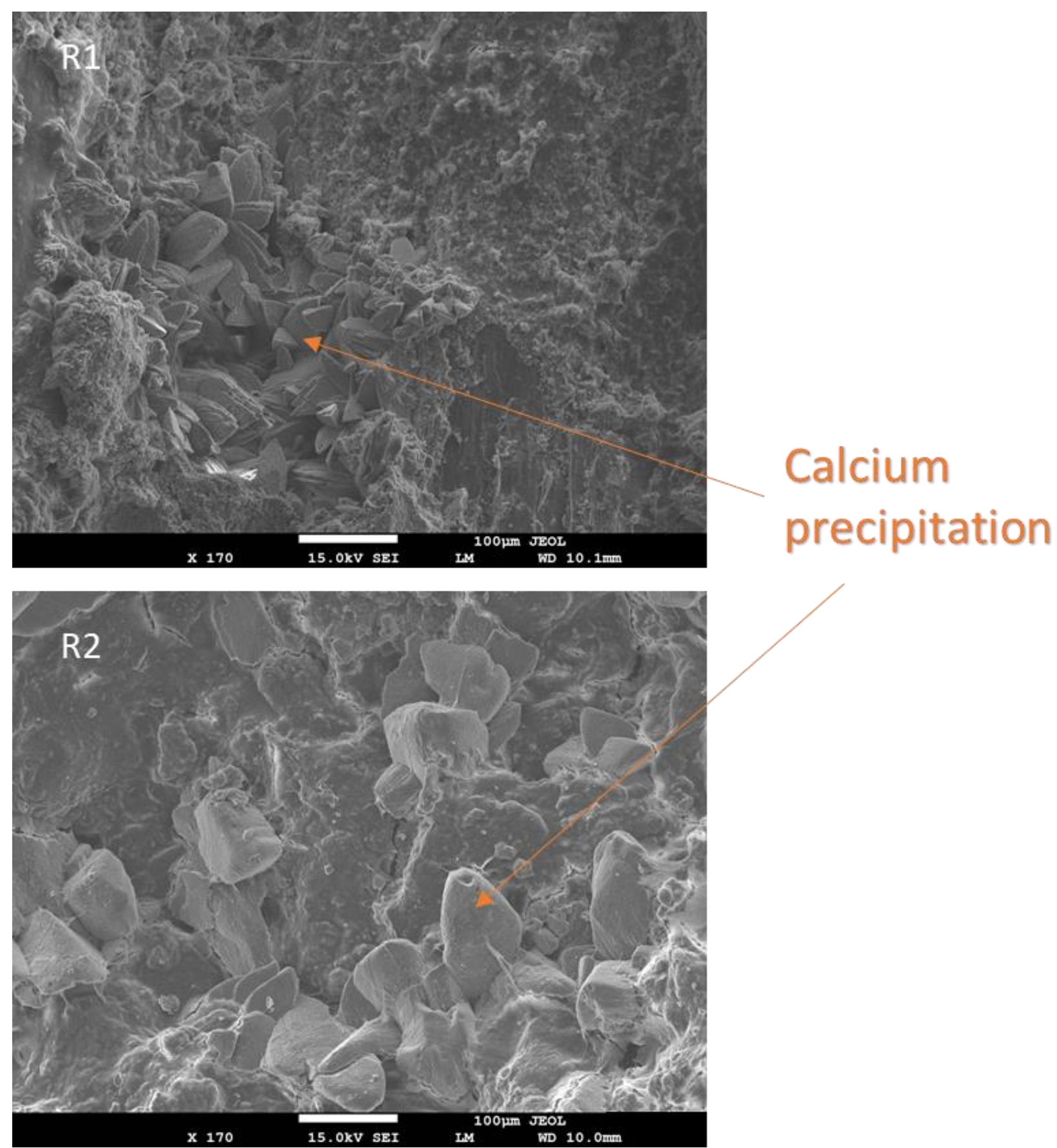

Figure $S 6$ Calcium precipitation observed on the surface of the biocathodes in R1 and R2. 
SI8. The Current and charge during milti-step polarization test
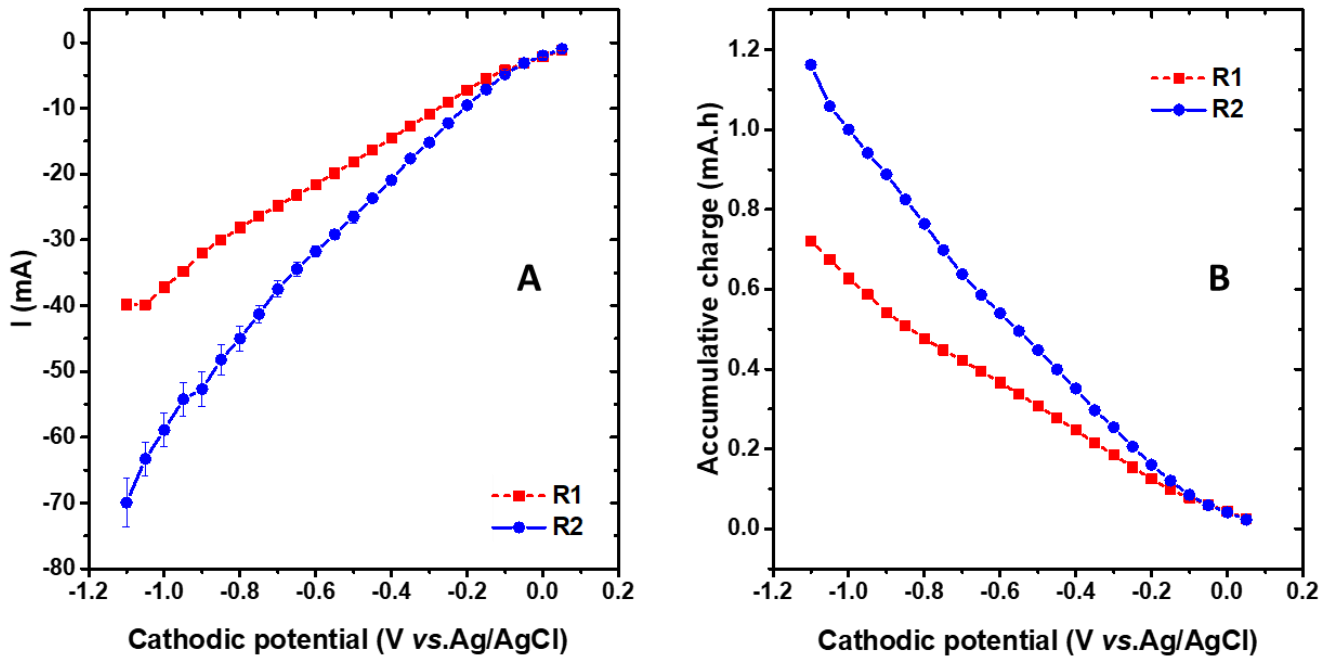

Figure S 7 Polarization curves recorded by successive chronoamperometry (CA) on day 403: A: the average of the faradaic current at each cathodic potential; B: the cumulative charge at each cathodic potential 
SI9 microbial characterization by Illumina 16S rRNA gene amplicon sequencing

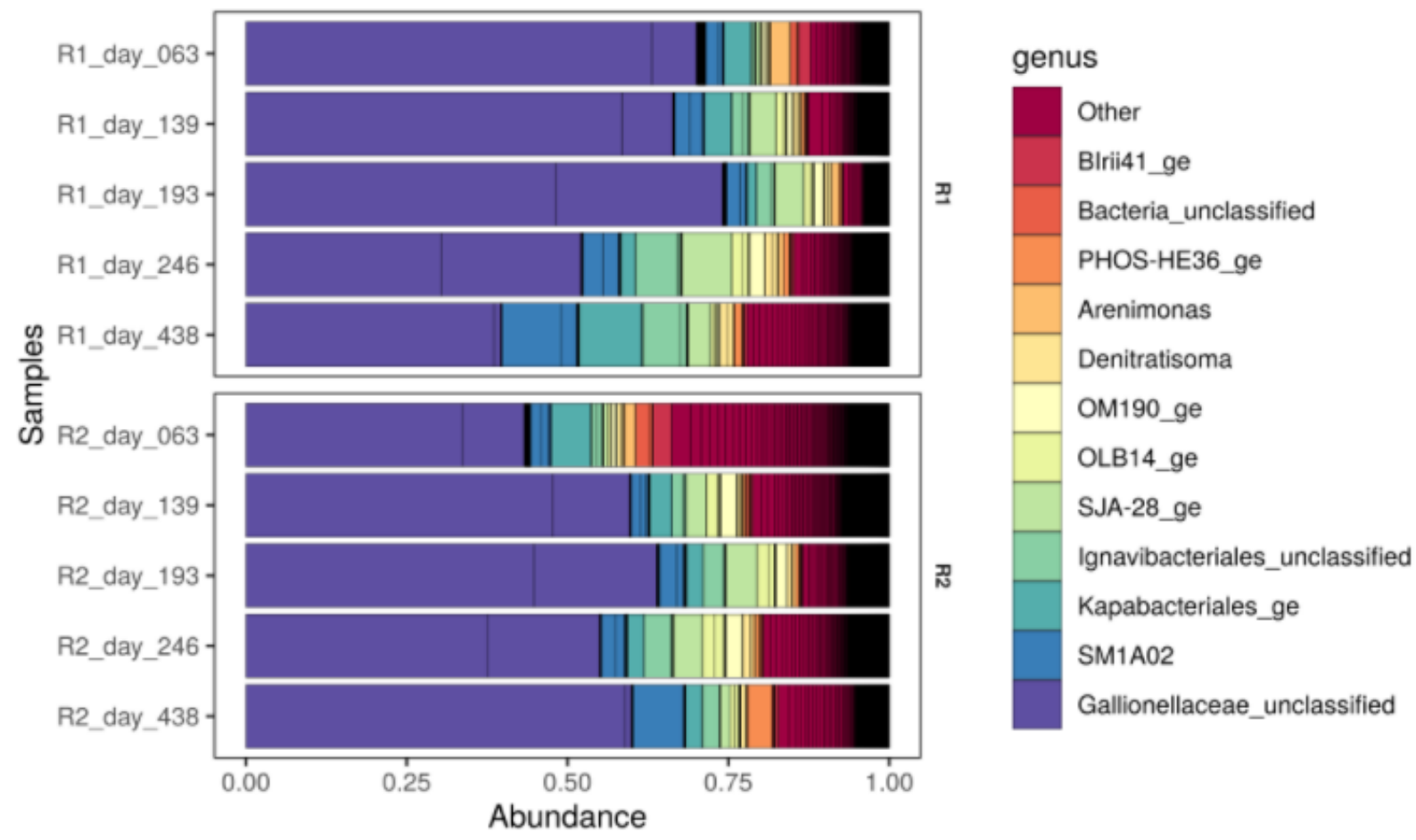

Figure $S 8$ Relative abundance of the top 12 genera as OTUs on cathodic biofilms of R1 and R2 on 5 different days along the reactor operation. The top 12 genera were calculated based on their combined relative abundance across all samples and plotted as OTUs, all other general were labeled as 'Other'. 
References:

(1) Roper, J. D.; Burton, D. L.; Madani, A.; Stratton, G. W. A Simple Method for Quantifying Dissolved Nitrous Oxide in Tile Drainage Water. Can. J. Soil Sci. 2013, 93 (1), 59-64. https://doi.org/10.4141/CJSS2012-021.

(2) Wang, X.; Jia, M.; Chen, X.; Xu, Y.; Lin, X.; Kao, C. M.; Chen, S. Greenhouse Gas Emissions from Landfill Leachate Treatment Plants: A Comparison of Young and Aged Landfill. Waste Manag. 2014, 34 (7), 1156-1164. https://doi.org/10.1016/j.wasman.2014.02.004.

(3) Weiss, R. F.; Price, B. A. Nitrous Oxide Solubility in Water and Seawater. Mar. Chem. 1980, 8 (4), 347-359. https://doi.org/10.1016/0304-4203(80)90024-9.

(4) Klindworth, A.; Pruesse, E.; Schweer, T.; Peplies, J.; Quast, C.; Horn, M.; Glöckner, F. O. Evaluation of General 16S Ribosomal RNA Gene PCR Primers for Classical and Next-Generation Sequencing-Based Diversity Studies. Nucleic Acids Res. 2013, 41 (1). https://doi.org/10.1093/nar/gks808.

(5) Wang, Q.; Garrity, G. M.; Tiedje, J. M.; Cole, J. R. Naïve Bayesian Classifier for Rapid Assignment of RRNA Sequences into the New Bacterial Taxonomy. Appl. Environ. Microbiol. 2007, 73 (16), 5261-5267. https://doi.org/10.1128/AEM.00062-07.

(6) De Paepe, K.; Kerckhof, F. M.; Verspreet, J.; Courtin, C. M.; Van de Wiele, T. Inter-Individual Differences Determine the Outcome of Wheat Bran Colonization by the Human Gut Microbiome. Environ. Microbiol. 2017, 19 (8), 3251-3267. https://doi.org/10.1111/14622920.13819.

(7) Zhao, W.; Fu, W.; Chen, S.; Xiong, H.; Lan, L.; Jiang, M.; Patil, S. A.; Chen, S. High-Capacitance Bioanode Circumvents Bioelectrochemical Reaction Transition in the Voltage-Reversed Serially-Stacked Air-Cathode Microbial Fuel Cell. J. Power Sources 2020, 468 (June), 228402. https://doi.org/10.1016/j.jpowsour.2020.228402. 
(8) Puigdomenech, I. Hydra/Medusa Chemical Equilibrium Database and Plotting Software. KTHRoyal Institute of Technology 2004.

(9) Clauwaert, P.; De Paepe, J.; Jiang, F.; Alonso-Fariñas, B.; Vaiopoulou, E.; Verliefde, A.; Rabaey, K. Electrochemical Tap Water Softening: A Zero Chemical Input Approach. Water Res. 2020, 169, 115263. https://doi.org/10.1016/J.WATRES.2019.115263.

(10) Sanjuán, I.; Benavente, D.; Expósito, E.; Montiel, V. Electrochemical Water Softening: Influence of Water Composition on the Precipitation Behaviour. Sep. Purif. Technol. 2019, 211, 857-865. https://doi.org/10.1016/j.seppur.2018.10.044.

(11) Gabrielli, C.; Maurin, G.; Francy-Chausson, H.; Thery, P.; Tran, T. T. M.; Tlili, M. Electrochemical Water Softening: Principle and Application. Desalination 2006, 201 (1-3), 150-163. https://doi.org/10.1016/j.desal.2006.02.012. 